\title{
STUDIES ON THE BIOSYNTHESIS OF CORDYCEPIN
}

NICHOLAS M. KREDICH AND ARMAND J. GUARINO

The Department of Biological Chemistry, The University of Michigan, Ann Arbor, Mich. (U.S.A.)

(Received August 8th, 1960)

\section{SUMMARY}

The carboxyl carbons of acetate and isovalerate do not serve to any appreciable extent as precursors of cordycepin, thus arguing against the origin of cordycepose from pathways of isoprenoid biosynthesis. Exogenously added $\left[8-{ }^{14} \mathrm{C}\right]$ adenine, $\left[\mathrm{I}^{-14} \mathrm{C}\right]-$ glucose, and $\left[{ }^{6-14} \mathrm{C}\right]$ glucose serve as excellent precursors, the latter two compounds labeling both the base and sugar of the nucleoside. $\left[6-{ }^{14} \mathrm{C}\right]$ glucose labels cordycepose better than $\left[\mathrm{I}^{14} \mathrm{C}\right]$ glucose, thereby indicating a loss of carbon atom number one of the glucose molecule in cordycepose synthesis.

\section{INTRODUCTION}

In I95 I CUNNINGHAM ct al. ${ }^{1}$ reported the isolation and characterization of an antibiotic, cordycepin, from liquid cultures of the mold Cordyceps militaris (Linn.) Link. In a subsequent paper by BENTLEY, CUNNINGHAM AND SPRING ${ }^{2}$ cordycepin was shown to be an adenine nucleoside containing a 3-deoxypentose with a branched carbon chain. Our interests in this compound have been<smiles></smiles>

Cordycepin

directed along two main lines. One of these has been to study the antitumor activity of cordycepin ${ }^{3}$, the other has been to investigate the biosynthetic pathways by which the mold produces this compound. This paper presents the results of our studies on the incorporation of various ${ }^{14} \mathrm{C}$-labeled compounds into cordycepin by intact cells.

\section{MATERIALS}

$\left[\mathrm{I}^{-14} \mathrm{C}\right]$ glucose and $\left[6-{ }^{14} \mathrm{C}\right] \mathrm{glucose}$ were purchased from the Volk Radiochemicals Corporation. $\left[8-{ }^{14} \mathrm{C}\right]$ adenine was obtained as a product in studies in which $\left[8-{ }^{14} \mathrm{C}\right]$ - 
guanine was converted to $\left.{ }^{[14} \mathrm{C}\right]$ hypoxanthine ${ }^{4}$. At the end of the incubation period in these experiments, all purines were liberated by acid hydrolysis and separated on a Dowex $-50-\mathrm{H}^{+}$column. The adenine fractions were pooled, concentrated, and rechromatographed on paper. The u.v.-absorbing material and the radioactivity were found superimposed on the paper when run in a solvent system of $86 \% n$-butanol. $\left[\mathrm{I}-{ }^{14} \mathrm{C}\right]$ ribose purchased from the National Bureau of Standards was kindly supplied by Dr. I. A. Bernstein. $\left[\mathrm{I}^{-14} \mathrm{C}\right]$ isovalerate, prepared by reacting isobutyl bromide with ${ }^{14} \mathrm{CO}_{2}$ by the Grignard reaction, was generously supplied by Dr. M. J. Coox. $\left[\mathbf{I}^{14} \mathrm{C}\right]$ acetate purchased from Tracer Laboratories Inc. was also kindly supplied by Dr. Coon. Enzymically prepared casein hydrolysate was purchased from Nutritional Biochemicals Inc.

Cordycepin was estimated either from its molar extinction $\left(\mathrm{I}_{4} \cdot \mathrm{IO}^{4}\right)$ at $26 \mathrm{o} \mathrm{m} \mu$ or by a modified anthrone procedure ${ }^{5}$, which is specific for cordycepose, the pentose moiety of cordycepin. Free cordycepose was determined by this anthrone method. Adenine was determined from its molar extinction (1.0.10 $\mathrm{O}^{4}$ in alkali) at $260 \mathrm{~m} \mu$. Glucose was determined according to $\mathrm{NELSON}^{6}$, and ribose by the orcinol procedure ${ }^{7}$.

Samples for determination of radioactivity were plated directly on stainless steel planchets and counted in a Nuclear gasflow Geiger counter with a micro-mil window using an automatic sample changer.

\section{EXPERIMENTAL}

Incubations were run in Roux bottles containing $200 \mathrm{ml}$ of medium composed of $0.5 \%$ casein hydrolysate and I \% glucose. Bottles were inoculated with Io $\mathrm{ml}$ of a $0.9 \%$ saline suspension of conidia. Approx. 2 days after inoculation subsurface growth was observed. In 3 days small surface colonies began to appear with the subsequent development of a well-formed pad by the end of 7 days. Aliquots were removed from the bottles periodically over a 3-week period, suspended mycelium removed by filtration and suitable dilutions made for absorbancy readings at $260 \mathrm{~m} \mu$. This increase in absorbancy of the medium is shown in Fig. I.

In a typical experiment the isotopic compound being tested was introduced into

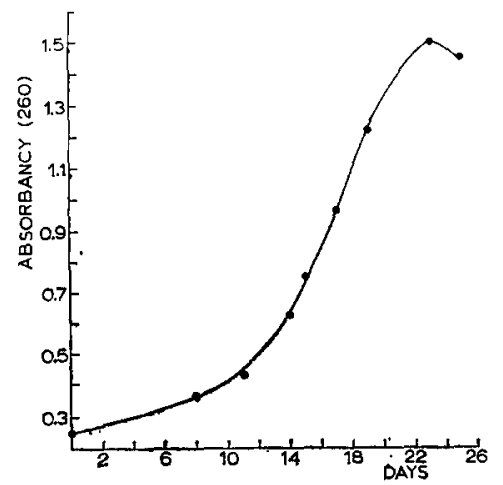

Fig. I. Change in absorbancy of medium during growth of Cordyceps militaris. 2-ml aliquot portions were withdrawn under sterile conditions and filtered free of mycelia. A I : 15 dilution of the filtrate was made with water and read against a water blank in a Beckman Model DU spectrophotometer at $260 \mathrm{~m} \mu$. 
the culture medium at a time when the absorbancy at $260 \mathrm{~m} \mu$ was beginning to increase rapidly. This usually occurred between ro and 14 days after inoculation. After a period of time varying between 3 and 7 days the mycelial material was removed by filtration, and the medium was concentrated to approx. $20 \mathrm{ml}$. This concentrate was filtered, adjusted to $\mathrm{pH}$ II and absorbed on a Dowex-I-Cl column, 200-400 mesh, X8 $\left(0.78 \mathrm{~cm}^{2} \times 8 \mathrm{~cm}\right)$. The cordycepin was eluted with deionized water until the absorbancy at $260 \mathrm{~m} \mu$ was less than 0.3 . Fractions containing cordycepin were pooled, and the amount of compound estimated from the extinction coefficient at $260 \mathrm{~m} \mu$. At this time $60-\mathrm{Ioo} \mathrm{mg}$ of recrystallized cordycepin were added as carrier. The volume was then reduced to 5-ro $\mathrm{ml}$, which resulted in the precipitation of crystalline cordycepin. This material was recrystallized to constant specific activity.

In experiments in which the distribution of isotope between the adenine and sugar moieties was determined the cordycepin was hydrolyzed by boiling an aqueous solution of the compound with Dowex-50W-H+, 200-400 mesh for $\mathrm{I} h$ in a water bath. The resin was removed by filtration and washed with water. The filtrate and washings were combined, and assayed for cordycepose by the anthrone method. The absorbancy of the solution at $260 \mathrm{~m} \mu$ indicated that $98-99 \%$ of the adenine remained on the resin, while $99 \%$ of the original cordycepose was recovered in this filtrate. An aliquot portion of this solution was taken for radioactivity determination.

The adenine was eluted from the resin with o.I $\mathrm{N} \mathrm{NH}_{4} \mathrm{OH}$. The eluate was concentrated under reduced pressure and the adenine concentration determined by its molar extinction coefficient. An aliquot portion of this solution was plated for radioactivity determination.

\section{RESULTS}

The isoprenoid carbon skeleton of cordycepose immediately suggested to us the possibility of its origin by way of demonstrated pathways of isoprenoid biosynthesis. As can be seen from the summary of our results in Table $I$, the carboxyl carbon atoms of acetate and isovalerate do not serve to any appreciable extent as precursors of cordycepin under the conditions of our experiments, although acetate was observed to be rapidly assimilated from the culture medium. $\left[{ }^{1-14} \mathrm{C}\right]$ ribose was also rapidly

\section{TABLE I}

COMPOUNDS UTILIZED IN CORDYCEPIN BIOSYNTHESIS

Incubations and isolation of cordycepin were carried out as described in the text. The specific activities given for cordycepin have been corrected for added carrier.

\begin{tabular}{|c|c|c|c|c|c|}
\hline . & \multicolumn{2}{|c|}{ Substance tested } & \multicolumn{2}{|c|}{ Cordycepin } & $\begin{array}{l}\text { Incubation } \\
\text { Time in days }\end{array}$ \\
\hline [I-14C] acetate & I I & I. 2 & $<\mathrm{I}_{5}$ & $<\mathrm{I} .2$ & 7 \\
\hline$[\mathrm{I}-14 \mathrm{C}] \mathrm{glucose}$ & 0.32 & 2.4 & 310 & I 5 & 3 \\
\hline$\left[6-{ }^{14} \mathrm{C}\right]$ glucose & 0.19 & 2.6 & 680 & 30 & 3 \\
\hline$\left[8-{ }^{14} \mathrm{C}\right]$ adenine & $1 \cdot 7$ & 0.53 & I900 & 80 & 7 \\
\hline
\end{tabular}


assimilated from the culture medium but failed to contribute a measurable quantity of its labeled carbon atom to cordycepin biosynthesis.

Carbons $I$ and 6 of glucose were found to be excellent precursors of cordycepin. Recorded in Tables I and II are the results of an experiment in which an attempt was made to compare the relative abilities of the number $I$ and 6 carbon atoms to serve as precursors. Two culture flasks were chosen which were as closely matched as possible

TABLE II

COMPARISON OF $\left[\mathrm{I}^{-14} \mathrm{C}\right]$ GLUCOSE AND [6-14C]GLUCOSE UTILIZATION

The hydrolysis of cordycepin and the determination of specific activities were carried out as described in the text. The incubations here are the identical ones described for $\left[\mathrm{I}-{ }^{14} \mathrm{C}\right]$ glucose and $\left[6-{ }^{14} \mathrm{C}\right]$ glucose in Table $\mathrm{I}$.

\begin{tabular}{|c|c|c|c|c|c|c|}
\hline & \multicolumn{2}{|c|}{ Precursor } & \multicolumn{2}{|c|}{ Cordycepose } & \multicolumn{2}{|c|}{ Adenine } \\
\hline & $\begin{array}{l}\text { Specific activity } \\
\text { counts/min/pmole }\end{array}$ & $\underset{\substack{\text { Total } \\
\text { counts } / \mathrm{min} \\
\times 10^{-6}}}{ }$ & $\begin{array}{l}\text { Specific activity } \\
\text { counts/min/ } / \text { umole }\end{array}$ & $\begin{array}{c}\text { Total } \\
\text { counts/min }\end{array}$ & $\begin{array}{l}\text { Specific activity } \\
\text { counts/min//mole }\end{array}$ & $\begin{array}{c}\text { Total } \\
\text { counts/min }\end{array}$ \\
\hline$\left[\mathrm{I}-{ }^{14} \mathrm{C}\right]$ glucose & 3,200 & 2.4 & I 60 & 7,700 & I 50 & 7,200 \\
\hline$[6-14 \mathrm{C}]$ glucose & 1,900 & 2.6 & 460 & 20,000 & 270 & 12,000 \\
\hline
\end{tabular}

in regard to age, development of mycelial pad (subjective comparison), glucose concentration and absorbancy at $260 \mathrm{~m} \mu$. Into one flask $\left[\mathrm{I}-{ }^{14} \mathrm{C}\right]$ glucose was introduced, while the other received $\left[6-{ }^{14} \mathrm{C}\right]$ glucose. The culture medium was then thoroughly mixed by gentle shaking, and aliquot portions were immediately withdrawn for the determination of glucose specific activity. After a 3 -day incubation cordycepin was isolated and assayed as previously described. The cordycepin was then hydrolyzed and the specific activities of the adenine and cordycepose were determined.

The results recorded in Table II indicate that the six position of glucose serves as a better precursor of cordycepin than the one position, and that the six position is utilized almost three times as well in cordycepose synthesis.

When $\left[8^{14} \mathrm{C}\right]$ adenine was tested as a precursor, it was found to be incorporated into cordycepin extremely well as indicated in Table $I$.

\section{DISCUSSION}

The biosynthesis of cordycepin by the mold Cordyceps militaris may be thought of to involve three individual problems: the synthesis of adenine, the synthesis of cordycepose, and the synthesis of the $\mathrm{N}$-glycosidic bond. The results of this study give some indication on the first two aspects of this problem, but at present give little information as to how, or at what stage in the overall synthesis the $\mathrm{N}$-glycosidic bond is established.

The fact that the mold does not require exogenously added purines for growth along with the observation that both $\left[\mathrm{I}^{14} \mathrm{C}\right]$ glucose and $\left[6-{ }^{14} \mathrm{C}\right]$ glucose resulted in significant labeling of the adenine shows that the purine part of the cordycepin molecule is synthesized de novo. The synthesis of the adenine has not been looked into further, and for the present we have assumed it occurs by conventional pathways established for the de novo synthesis of purines. 
The carbon skeleton of cordycepose, the pentose moiety of cordycepin, is in essence that of isoprene. It seemed possible, therefore, that this part of the molecule might arise from pathways involved in isoprenoid biosynthesis. The failure of $\left[\mathrm{I}-{ }^{14} \mathrm{C}\right]-$ acetate and carboxyl-labeled isovalerate to label cordycepin, in addition to the excellent labeling of this compound by either $\left[{ }^{1-14} \mathrm{C}\right]$ glucose or $\left[6-{ }^{14} \mathrm{C}\right]$ glucose tends to rule out the possibility that the synthesis of cordycepose is from pathways of lipid metabolism. However, even though we found $\left[\mathrm{I}^{-14} \mathrm{C}\right]$ acetate to be assimilated by this organism, it is possible that the mold does not possess an activating system for converting acetate to acetyl-CoA. The same may be true for isovalerate, although here a permeability phenomenon may also be a problem. We tend to take the view at the present time that cordycepose synthesis does not take place by pathways involving isoprenoid biosynthesis.

The comparison of the labeling of cordycepose from $\left[\mathrm{I}^{-14} \mathrm{C}\right]$ glucose and $\left[6-{ }^{14} \mathrm{C}\right]-$ glucose as recorded in Table II indicates a threefold better incorporation from the C6-labeled than the $\mathrm{C}_{\mathrm{I}}$-labeled glucose. This incorporation into cordycepose occurred with only a four-fold dilution of specific activity in the case of $\left[6-{ }^{14} \mathrm{C}\right]$ glucose. Considering the fact that a 3 -day incubation was employed in this experiment, it would appear that glucose is not too remote a precursor in cordycepose biosynthesis. The poorer incorporation from $\left[\mathrm{I}-{ }^{14} \mathrm{C}\right]$ glucose implies a loss of this position at some point in the synthesis. Perhaps a pathway identical or similar to the hexosemonophosphate shunt pathway is operative in the synthesis of this pentose. In support of this we have been able to demonstrate glucose 6-phosphate dehydrogenase and 6-phosphogluconic dehydrogenase activities in extracts prepared from this organism.

The fact that exogenously added adenine is well incorporated into cordycepin shows that the organism has a means of utilizing intact purines in cordycepin biosynthesis. The synthesis of the nucleoside from the base and sugar may be envisioned to take place by one or both of two possible routes. The first of these would involve a synthesis of the purine and sugar by separate pathways with an ultimate condensation between the two to establish the nucleoside. This would be analogous to reactions established in other organisms in which purines react with ribose I-phosphate in the presence of nucleoside phosphorylase ${ }^{8}$ to give nucleosides, or with phosphoribosylpyrophosphate in the presence of nucleotide pyrophosphorylase ${ }^{9}$ to give nucleotides. The second possible route of synthesis of the nucleoside might involve a pathway in which the base or precursor to the base is attached to the sugar or precursor to the sugar at an early stage in the synthesis. The completion of the purine ring and further synthesis of the sugar would then take place simultaneously while the N-glycosidic bond remained intact. This proposed pathway is analogous to the de novo synthesis of the purine ring system, where the pentose phosphate moiety is added at an early stage in the synthesis.

Work in our laboratory is now being directed at the problem of the origin of the glycosidic bond of cordycepin. Attempts to obtain a cell-free preparation of the mold capable of synthesizing cordycepin have met with little success.

\section{ACKNOWLEDGEMENTS}

This work was supported in part by a grant from the National Science Foundation, NSF G-6423. The first author is a post-sophomore research medical student fellow of 
the United States Public Health Service. We wish to express our appreciation to Mrs. M. DEwEy for her technical assistance in this work.

\title{
REFERENCES
}

1 K. G. Cunningham, S. A. Hutchinson, W. Manson and F. S. Spring, J. Chem. Soc., 2299 (I951).

2 H. R. Bentley, K. G. Cunningham and F. S. Spring, J. Chem. Soc., 230 i (I95i).

3 N. M. Kredich, D. V. Jagger and A. J. Guarino, Federation Proc., ig (I960) 394.

4 A. J. Guarino and G. Yuregir, Biochim. Biophys. Acta, 36 (I959) I 57.

5 N. M. Kredich and A. J. Guarino, Biochim. Biophys. Acta, 4 I (1960) 363.

6 N. Nelson, J. Biol. Chem., I 53 (I944) 375.

7. W. Mejbaum, Z. physiol. Chem., Hoppe-Seyler's, 258 (I939) I 17.

8 H. M. Kalckar, J. Biol. Chem., I67 (I947) 477.

9 A. Kornberg, I. Lieberman and E. S. Simms, J. Am. Chem. Soc, 76 (1954) 2027.

Biochim. Biophys. Acta, 47 (1961) 529-534

\section{TWO-STAGE CONTRACTION IN RAT-TAIL TENDON}

\author{
B. J. RIGBY
}

CSIRO Wool Research Laboratories, Division of Textile Physics, Ryde, N.S.W. (Australia)

(Received July 22nd, I960)

\section{SUMMARY}

The contraction of rat-tail tendon in solutions of certain hydrogen-bond and ionic-bond breaking reagents was found to occur in two stages. The second stage always began at a temperature within the range $37-40^{\circ}$. This behaviour was shown to correlate with earlier work on the mechanical properties of rat-tail tendon, in which a transition temperature within the above range was found. Both sets of experiments are discussed in terms of the well known axial band structure of the collagen fibril.

\section{INTRODUCTION}

When heated in water or $0.9 \% \mathrm{NaCl}$ solution, rat-tail tendon exhibits an abrupt contraction at approx. $60^{\circ}$ to about 0.25 of its original length. This is known as the shrinkage temperature, and has been studied for many years ${ }^{1}$. Another less generally recognised contraction takes place in tendon when it is placed in acid or alkaline solution, or in solutions of hydrogen-bond-breaking reagents such as urea. This type of contraction, which is of the order of $10-20 \%$ of the original length of the tendon (measured in $0.9 \%$ saline), is usually associated with a diametral swelling. It also has been extensively studied ${ }^{1}$, but as mentioned earlier, the associated contraction appears to have been somewhat overlooked. The purpose of this note is to present some simple experiments concerning this second type of contraction and to discuss its possible relation to the structure of tendon and also to experiments reported elsewhere. These 